
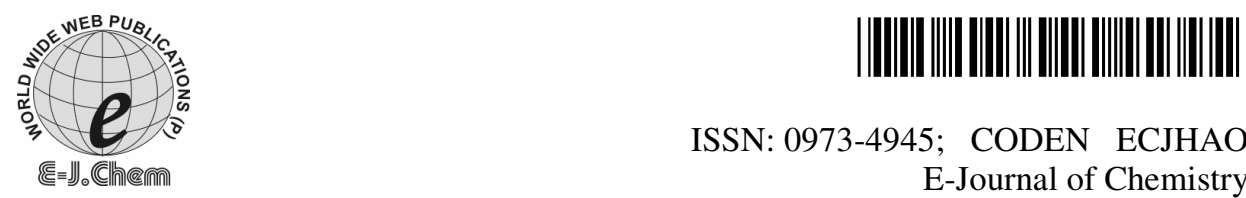

ISSN: 0973-4945; CODEN ECJHAO

E-Journal of Chemistry

http://www.e-journals.net 2009, 6(2), 429-436

\title{
Hydro-chemical Survey of Groundwater of Delhi, India
}

\author{
MASOOD ALAM, SUMBUL RAIS ${ }^{*}$ and MOHD ASLAM \\ Department of Applied Sciences \& Humanities, \\ Faculty of Engineering and Technology, \\ Jamia Millia Islamia, New Delhi-110025, India. \\ sumbulrais@gmail.com
}

Received 9 July 2008; Revised 15 September 2008; Accepted 11 October 2008

\begin{abstract}
The physicochemical parameters and trace metal contents of water samples from Delhi were assessed. A total of 20 water samples were collected from boring, tube well and hand pump and analyzed for the various physicochemical parameters like $\mathrm{pH}$, conductivity, total dissolved solid, total alkalinity, $\mathrm{Ca}^{2+}$ and $\mathrm{Mg}^{2+}$ hardness, chloride ion, dissolved oxygen, biochemical oxygen demand, sulphate and heavy metal contents like $\mathrm{Cu}, \mathrm{Cr}, \mathrm{Cd}, \mathrm{Co}, \mathrm{Zn}$ and Ni. The results were compared with BIS standards for drinking water. The quality of water samples under study were within the maximum permissible limits. Therefore, the groundwater samples are fit for human consumption without prior treatment.
\end{abstract}

Keywords: Physicochemical parameters, Trace metals, BIS limits, Groundwater, Delhi.

\section{Introduction}

Groundwater is water that occupies the pores or crevices in sand, sandstone, limestone and other rocks ${ }^{1}$. The crucial role which groundwater plays as a decentralized source of drinking water for millions of rural and urban families cannot be overstated. According to some estimates, it accounts for nearly 80 percent of the rural domestic water needs and 50 percent of the urban water needs in India 2 .

In Delhi, drinking water supply is not from single source. Sixty eight percent of the population is getting supply from water of Yamuna River. Groundwater has also other sources like tube wells, hand pump and boring ${ }^{3}$. But the quantity of good quality fresh groundwater available for the use without depleting our stores or damaging the environment is much less. This means that it is very important to protect these resources from pollution as most of the times groundwater is directly used. Business owners, municipalities and the public should understand that contamination can enter the groundwater from many routes ${ }^{4}$. 
The resulting groundwater contamination plumes may extend several hundred meters or even further away from the source of pollution. As groundwater move both vertically and horizontally in response to gravity and hydraulic pressure.

As the assessment of groundwater quality has not been given due importance, water borne diseases have become very common. About 80 percent of the diseases in the world are due to poor quality of drinking water ${ }^{5}$. The focus and purpose of the present monitoring exercise was to assess the degree of contamination level in groundwater of Delhi.

\section{The study area}

\section{Location \& climate}

The study area spreads in an area of 1,483 sq Km (573 sq mile), of which 783 sq Km (302 sq mil) is designated rural and $700 \mathrm{sq} \mathrm{Km}\left(270 \mathrm{sq}\right.$ mil) as urban lying between latitude $28.38^{\circ}$ $\mathrm{N}$ and longitude $77.12^{\circ} \mathrm{E}$ with an expected population of 17.5 million by the end of the $10^{\text {th }}$ five year plan.

Climate of Delhi is semi-arid with high variation between summer $\left(25\right.$ to $\left.46{ }^{\circ} \mathrm{C}\right)$ and winter (22 to $5{ }^{0} \mathrm{C}$ ) temperatures. Summers are long, from early April to October, with the monsoon season in between. The average rainfall is approximately $714 \mathrm{~mm}$ (28.1 inches).

\section{Physiogeography}

Two prominent features of the geography of Delhi are the Yamuna flood plain and the Delhi ridge. The low lying Yamuna flood plains provide fertile alluvial soil derived from the adjacent quartzite ridge, suitable for agriculture. However, these plains are prone to recurrent floods. This

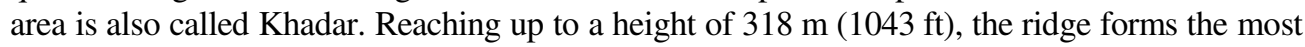
dominating physiographic feature in this region. It originates from the Aravalli Range and consists of quartzite rocks in the south and encircles the west, northeast and northwest parts of the city. Leaving aside the Yamuna flood plain (khadar) and the ridge, the entire area of the national capital territory of Delhi is categorized as Bangar or the plain. A major proportion of the area of Delhi is plain and on this are located Delhi, New Delhi and Delhi cantonment along with a vast stretch of numerous villages. The land of the plain is mostly fertile. Most of the city, including New Delhi, lies west of the river. East of the river is the urban area of Shahdara. Delhi falls under seismic zone-IV, making it vulnerable to major earthquakes.

\section{Soil classification \& distribution}

The soils of the Delhi area are mostly light with subordinate amount of medium texture soils. The light texture soils are represented by sandy, loamy, sand and sandy loam; whereas medium texture soils are represented by silty loam. The soils that occur in all the blocks are generally suitable for irrigating moderately salt resistant crops such as wheat, barley and mustard.

\section{Methodology}

Twenty samples were collected from tube wells, hand pumps and borings that draw water from groundwater. These were analyzed for major ion chemistry, employing the standard methods $^{6}$ (APHA).

Hydrogen ion concentration (pH), total dissolved solid (TDS) and conductivity were measured, using $\mathrm{pH}$, TDS and conductivity meters respectively.

Total alkalinity (TA) were estimated titrimetrically using $\mathrm{HCl}$. Total hardness (TH) and calcium $\left(\mathrm{Ca}^{2+}\right)$ were analyzed titrimetrically using standard EDTA. Magnesium $\left(\mathrm{Mg}^{2+}\right)$ was 
computed taking the difference between $\mathrm{TH}$ and $\mathrm{Ca}^{2+}$ values. Chloride $\left(\mathrm{Cl}^{-}\right)$was estimated using standard $\mathrm{AgNO}_{3}$ titration while sulphate $\left(\mathrm{SO}_{4}{ }^{2-}\right)$ were analyzed with the help of spectrophotometer?

Dissolved oxygen (DO) and biochemical oxygen demand (BOD) were analyzed titrimetrically using standard sodium thiosulphate $\left(\mathrm{Na}_{2} \mathrm{~S}_{2} \mathrm{O}_{3}\right)$ solution. For copper, chromium, cadmium, cobalt, zinc and nickel determination in water samples an air acetylene flame was used and the analysis was carried out using Atomic Absorption Spectrophotometer (AAS), Perkin Elmer model 3100. All glassware used for the analyses were carefully cleaned with nitric acid followed by thorough rinsing with double distilled water before use. All reagents used were of analytical grade. Double distilled water was used throughout the study.

\section{Results and Discussion}

The monitoring started with collection and assessment of water sample from the site of collection by measuring the temperature of the sample ranging from $27-32^{\circ} \mathrm{C}$ with day temperature $26^{\circ} \mathrm{C}(\min )$ to $38{ }^{\circ} \mathrm{C}(\max )$. All the readings are given in Table 1 .

Table 1. The results of various physicochemical analyses of groundwater samples of Delhi.

\begin{tabular}{|c|c|c|c|c|c|c|c|c|c|c|c|c|}
\hline S.No & $\begin{array}{l}\text { Sampling } \\
\text { Point }\end{array}$ & Type & $\mathrm{pH}$ & $\mathrm{EC}$ & TDS & Alkalinity & $\mathrm{Ca}^{2+}$ & $\mathrm{Mg}^{2+}$ & $\mathrm{Cl}^{-}$ & DO & BOD & $\mathrm{SO}_{4}{ }^{2-}$ \\
\hline 1 & Sultanpuri & B & 7.4 & 1.06 & 310 & 440 & 126 & 66 & 93.18 & 7.14 & 1.86 & 17 \\
\hline 2 & Mandi & B & 7.6 & 2.27 & 642 & 480 & 112 & 26 & 350.56 & 9.69 & 0.44 & 49 \\
\hline 3 & Chattarpur & B & 7.4 & 0.722 & 236 & 430 & 92 & 38 & 31.06 & 7.85 & 1.46 & 14 \\
\hline 4 & Bhati Gao & $\mathrm{B}$ & 7.3 & 0.812 & 237 & 350 & 108 & 44 & 39.93 & 8.97 & 1.66 & 14.5 \\
\hline 5 & Fatehpur Beri & $\mathrm{HP}$ & 7.4 & 0.991 & 294 & 480 & 178 & 34 & 62.125 & 8.46 & 1.86 & 10.5 \\
\hline 6 & Alipur & HP & 7.4 & 3.42 & 970 & 360 & 200 & 220 & 536.93 & 8.87 & 1.04 & 66.5 \\
\hline 7 & Singhola & $\mathrm{HP}$ & 7.6 & 3.24 & 879 & 460 & 178 & 248 & 448.18 & 6.12 & 2.99 & 62.5 \\
\hline 8 & Lampur & TW & 7.5 & 4.4 & 1250 & 450 & 176 & 188 & 674.5 & 7.44 & 2.58 & 66 \\
\hline 9 & Singhu border & TW & 7.3 & 2.4 & 650 & 350 & 96 & 214 & 301.75 & 8.26 & 2.17 & 58.5 \\
\hline 10 & Bhakhtawar pur & TW & 7.4 & 4.42 & 1250 & 310 & 234 & 216 & 931.87 & 8.36 & 1.76 & 68 \\
\hline 111 & Burari & HP & 7.3 & 2.45 & 685 & 400 & 150 & 146 & 381.62 & 7.95 & 2.48 & 67.5 \\
\hline 12 & Matiala & $\mathrm{B}$ & 7.5 & 2.68 & 737 & 330 & 140 & 100 & 612.37 & 9.08 & 2.07 & 43 \\
\hline 13 & Nawada & $\mathrm{B}$ & 7.7 & 2.33 & 642 & 590 & 48 & 178 & 257.37 & 6.22 & 3.9 & 62.5 \\
\hline 14 & Yamuna Vihar & HP & 7.8 & 0.954 & 254 & 350 & 52 & 90 & 31.06 & 7.32 & 0.816 & 39.5 \\
\hline 15 & Mangolpuri Ind & HP & 7.8 & 2.91 & 757 & 650 & 74 & 68 & 417.12 & 3.16 & 3.02 & 71 \\
\hline 16 & Karala & B & 7.8 & 2.6 & 687 & 520 & 74 & 140 & 257.37 & 5.5 & 1.22 & 72.5 \\
\hline 17 & Kanjhawala & $\mathrm{HP}$ & 7.7 & 0.711 & 190 & 260 & 96 & 22 & 26.26 & 2.85 & 0.52 & 46 \\
\hline 181 & Khod Punjab & HP & 8.5 & 1.35 & 362 & 470 & 12 & 10 & 53.25 & 4.08 & 3.59 & 65 \\
\hline 19 & Qutab Garh & HP & 8.2 & 5.16 & 1430 & 860 & 10 & 12 & 860.87 & 4.38 & 2.95 & 73.5 \\
\hline 201 & Bawana & HP & 7.6 & 3.13 & 831 & 750 & 54 & 70 & 394.93 & 3.16 & 0.96 & 69.5 \\
\hline
\end{tabular}

$\underline{\mathrm{B}=\text { Boring, } \mathrm{TW}=\text { Tube Well, HP }=\text { Hand Pump Except } \mathrm{pH} \& \mathrm{EC}(\mathrm{mS} / \mathrm{cm}) \text { all units are in ppm }}$

The groundwater sample shows $\mathrm{pH}$ values from 7.26 to 8.46 lying within the recommended values ( 6.5 to 8.5 ) for domestic use. The conductivity was found to be varied from $0.711-5.16(\mathrm{mS} / \mathrm{cm})$ as shown in Figure 1. 


\section{I $\mathrm{pH}$ Conductance}

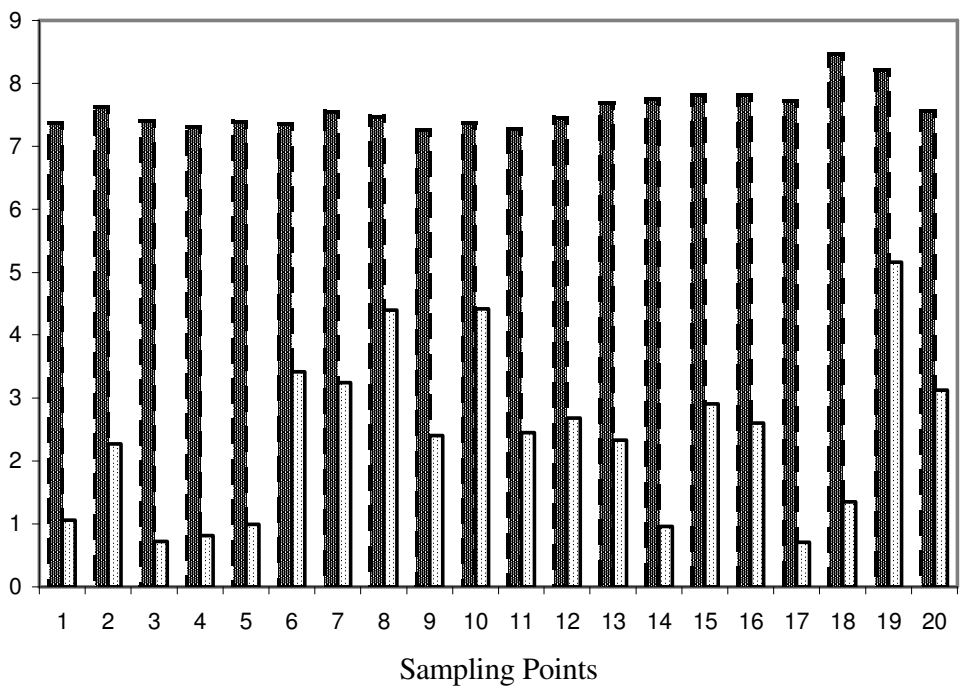

Figure 1. pH and conductance of various groundwater samples collected from Delhi.

Total hardness $\left(\mathrm{Ca}^{2+}\right.$ plus $\left.\mathrm{Mg}^{2+}\right)$ of the samples falls in the different categories. Majority of which $(11 \%)$ belong to very hard category having $\mathrm{TH}$ more than $180 \mathrm{ppm}$. $7 \%$ of the samples fall under hard water $120-180 \mathrm{ppm}$ and rest $10 \%$ falling to soft water category $(0-60$ ppm) not even a single sample has hardness in medium range 60-120 ppm. If we see $\mathrm{Ca}^{2+}$ and $\mathrm{Mg}^{2+}$ only two samples are within permissible limit of 75 and $30 \mathrm{ppm}$ respectively.

Total alkalinity values changed from $260-860 \mathrm{ppm}$ (Figure 2). All the water samples were found above maximum desirable limit of $200 \mathrm{ppm}$, but only $15 \%$ shows values above permissable limit i.e $600 \mathrm{ppm}$ and the rest comprising $85 \%$ are within permissible limits.

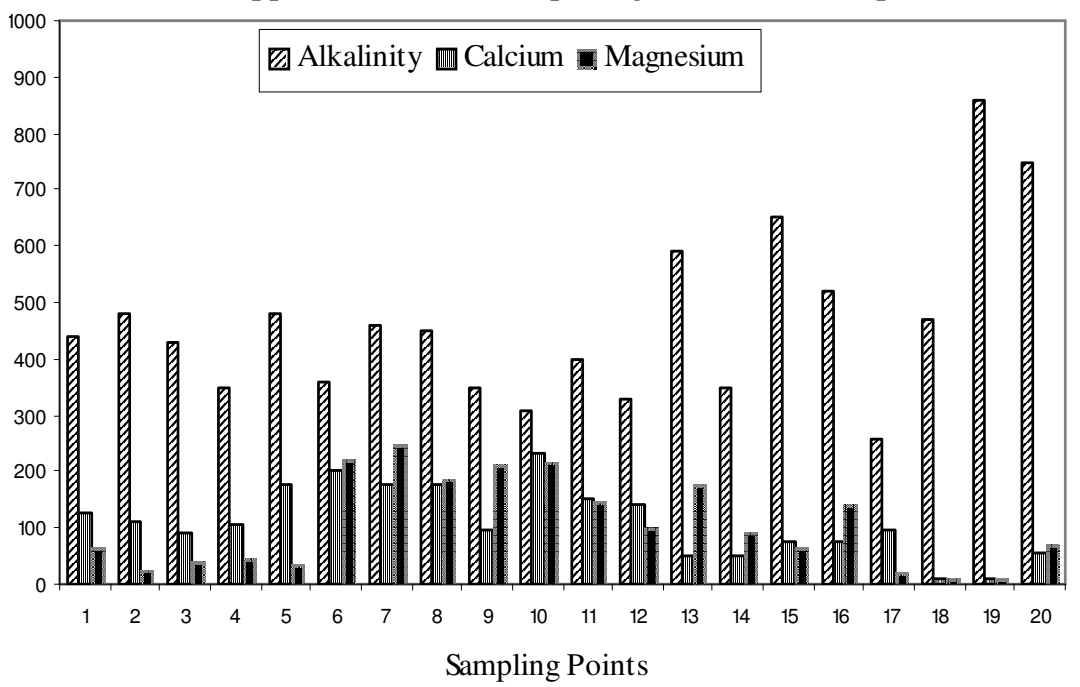

Figure 2. Alkalinity and Hardness of various groundwater samples collected from Delhi. 
Figure 3 shows the too high contents of dissolved oxygen which is an indication of organic pollution and the values ranged from 2.85 at kanjhawala to 9.69 at Mandi with the variation of BOD values of 0.44 at Mandi and 3.90 of Nawada water sample.

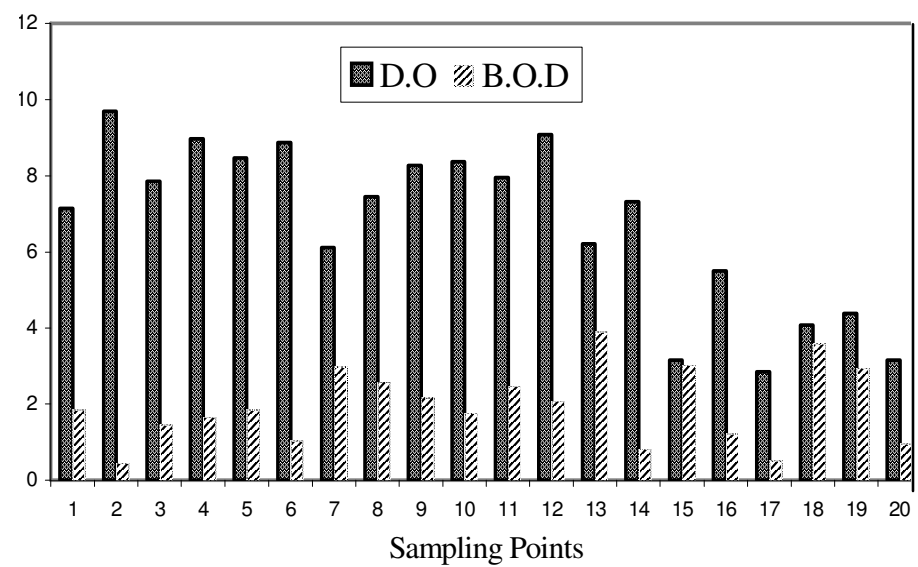

Figure 3. D.O and B.O.D values of various groundwater samples collected from Delhi.

Acccording to the TDS classification, the majority of the samples (85\%) are fresh water with TDS less than $1000 \mathrm{ppm}$. The remaining samples (15\%) are of brakish type with TDS greater than $1000 \mathrm{ppm}$. But only $25 \%$ are found within the BIS standard drinking water desirable limit of 300 ppm. A relationship between TDS and anion concentration $\left(\mathrm{Cl}^{-}\right)$was observed in the performed experiment which is shown in Figure 4. In most of the cases when $\mathrm{Cl}^{-}$ion concentration is more the TDS is also more. $\mathrm{Cl}^{-}$ion was found high in Qutab garh sample as 860.87 ppm TDS was also reported high as $1430 \mathrm{ppm}$. Bhakhtawarpur water sample have high values of $931 \mathrm{ppm} \mathrm{Cl}^{-}$ion and $1250 \mathrm{ppm}$ TDS. Some sites like Yamuna Vihar and Chattarpur show $\mathrm{Cl}^{-}$ion conc. as $31.06 \mathrm{ppm}$, while TDS is 254 and 236 ppm respectively. At Kanjhawala $\mathrm{Cl}^{-}$and TDS were reported as 26.26 ppm and 190 ppm respectively. The values of $\mathrm{Cl}^{-}$ion are under desirable limits of $250 \mathrm{ppm}$.

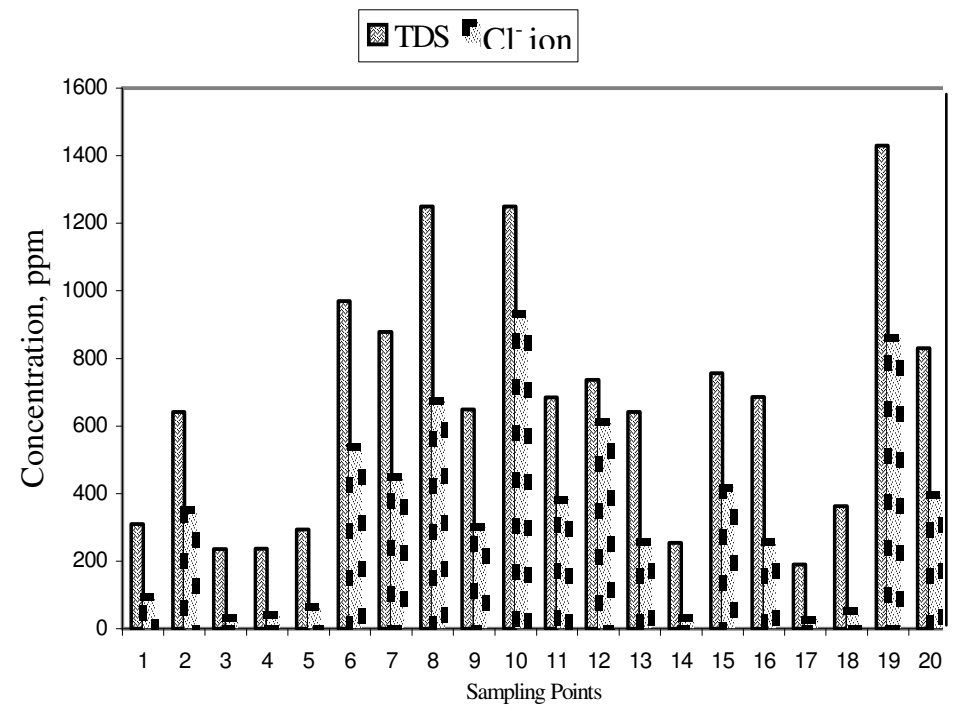

Figure 4. TDS and $\mathrm{Cl}^{-}$ion values of various groundwater samples collected from Delhi. 
The highest sulphate value was recorded at Qutab Garh (73.5 ppm) and the lowest at Fatehpur Beri (10.5 ppm). The desirable limits of sulphate are $250 \mathrm{ppm}$ (Figure 5).

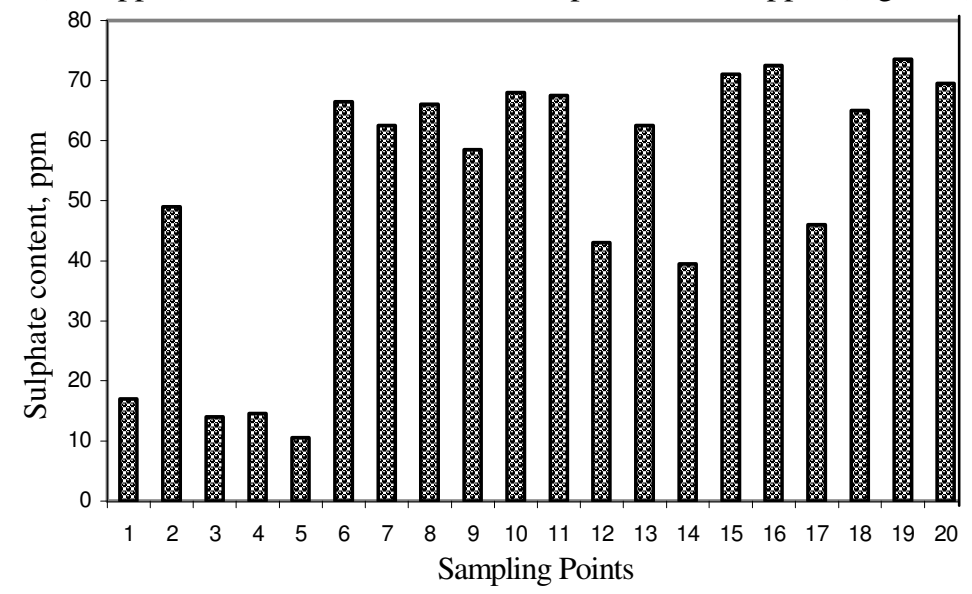

Figure 5. Sulphate content of various groundwater samples collected from Delhi.

The concentration of heavy metals in water samples are given in Table 2. $\mathrm{Cu}$ concentration ranged from 0.04 to $0.01 \mathrm{ppm}$. Out of the trace metals, $\mathrm{Zn}$ is always in abundance in water with values ranging from $2.56-0.04 \mathrm{ppm}$.

Table 2. Concentration of heavy metals in groundwater samples of Delhi.

\begin{tabular}{rlcllccc}
\hline S.No & \multicolumn{1}{c}{$\begin{array}{c}\text { Sampling } \\
\text { Point }\end{array}$} & $\begin{array}{c}\text { Cu } \\
\text { ppm }\end{array}$ & $\begin{array}{c}\text { Cr } \\
\text { ppm }\end{array}$ & $\begin{array}{c}\text { Cd } \\
\text { ppm }\end{array}$ & $\begin{array}{c}\text { Co } \\
\text { ppm }\end{array}$ & $\begin{array}{c}\text { Zn } \\
\text { ppm }\end{array}$ & $\begin{array}{c}\text { Ni } \\
\text { ppm }\end{array}$ \\
\hline 1 & Sultanpuri & BDL & BDL & BDL & 0.05 & 0.05 & 0.04 \\
2 & Mandi & 0.01 & BDL & BDL & 0.08 & 0.12 & 0.07 \\
3 & Chattarpur & BDL & BDL & 0.03 & 0.07 & 0.05 & 0.06 \\
4 & Bhati Gao & BDL & BDL & BDL & 0.07 & 0.54 & 0.07 \\
5 & Fatehpur Beri & 0.03 & BDL & BDL & 0.08 & 2.56 & 0.14 \\
6 & Alipur & BDL & BDL & BDL & 0.09 & 0.18 & 0.11 \\
7 & Singhola & BDL & BDL & BDL & 0.12 & 1.44 & 0.08 \\
8 & Lampur & BDL & BDL & BDL & 0.16 & 0.12 & 0.1 \\
9 & Singhu border & BDL & BDL & BDL & 0.12 & 0.05 & 0.1 \\
10 & Bhakhtawar pur & BDL & BDL & BDL & 0.2 & 0.07 & 0.12 \\
11 & Burari & BDL & BDL & BDL & 0.14 & 0.05 & 0.09 \\
12 & Matiala & 0.01 & BDL & BDL & BDL & 0.06 & 0.12 \\
13 & Nawada & BDL & BDL & BDL & BDL & 0.06 & 0.09 \\
14 & Yamuna Vihar & BDL & BDL & BDL & 0.03 & 0.2 & 0.09 \\
15 & Mangolpuri Ind & BDL & BDL & BDL & 0.03 & 0.29 & 0.08 \\
16 & Karala & BDL & BDL & 0.01 & 0.01 & 1.18 & 0.1 \\
17 & Kanjhawala & 0.04 & BDL & BDL & BDL & 0.08 & 0.09 \\
18 & Khod Punjab & 0.01 & BDL & BDL & BDL & 0.07 & 0.11 \\
19 & Qutab Garh & BDL & BDL & BDL & 0.04 & 0.27 & 0.15 \\
20 & Bawana & BDL & 0.01 & BDL & 0.03 & 0.04 & 0.16 \\
BDL= Below Detection Limit & & & & & \\
\hline
\end{tabular}


The highest concentration of $\mathrm{Zn}$ was recorded at Fateh Pur Beri (2.56 ppm) but the value falls within permissible limit of $15 \mathrm{ppm}$ according to BIS. Co was under detection limits and the values varied from 0.2 to $0.01 \mathrm{ppm}$ and in some cases as zero. Cr was not detected in almost all the samples except in one sample of Bawana as $0.01 \mathrm{ppm}$ which is well within BIS Maximum Desirable Limit of $0.05 \mathrm{ppm}$. Cd was detected only in two samples as 0.03 and $0.01 \mathrm{ppm}$ at chattarpur and Karala respectively. The concentrations in all the remaining samples were below detection limit of the instrument. Ni was recorded with the maximum value of $0.16 \mathrm{ppm}$ and the minimum value of $0.04 \mathrm{ppm}$ (Figure 6).

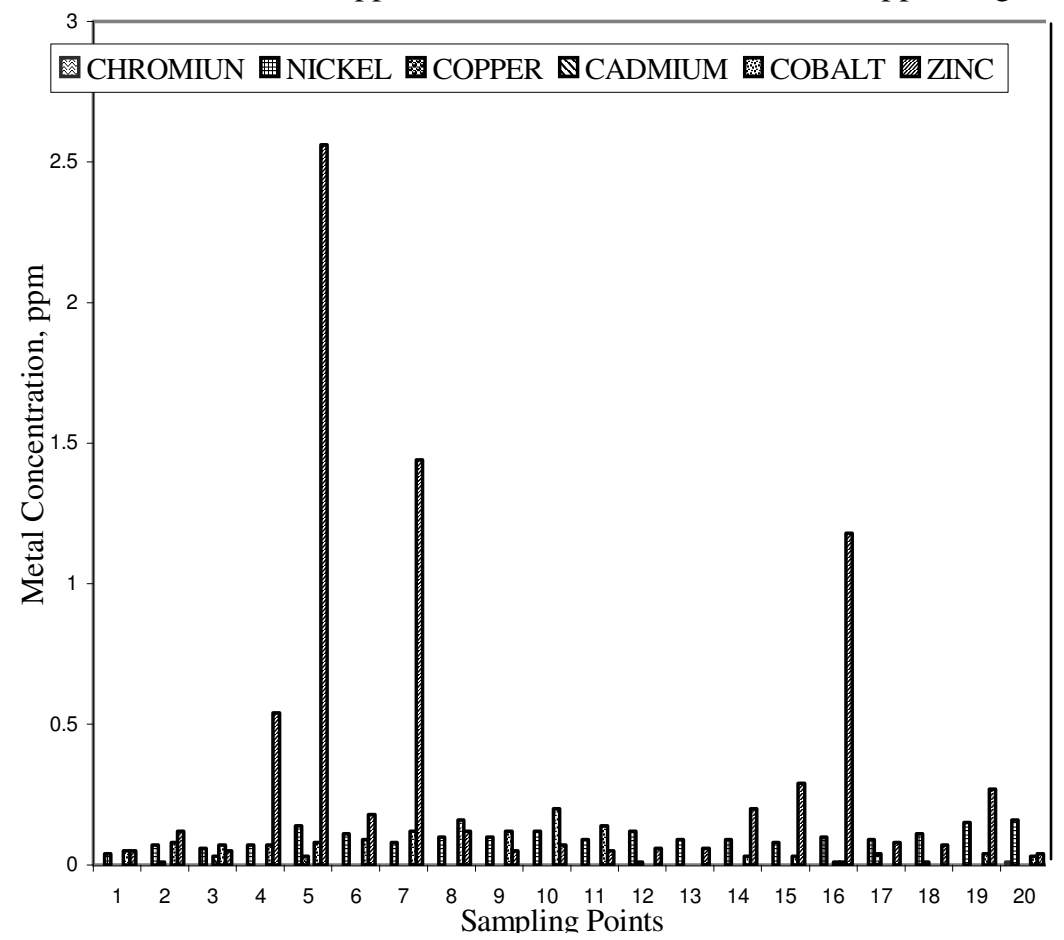

Figure 6. Heavy Metal content (ppm) in various groundwater samples of Delhi.

\section{Conclusion}

The present investigation has led us to conclude that the quality of water samples subjected to study was acceptable for majority of physicochemical parameters as it falls within the maximum permissible limits of drinking water of BIS. Among heavy metals $\mathrm{Zn}, \mathrm{Ni}$, \& $\mathrm{Co}$ were found more than $\mathrm{Cu}, \mathrm{Cr} \& \mathrm{Cd}$. From the findings it may be concluded that the groundwater samples are fit for human consumption without prior treatment.

\section{References}

1. Water Facts- water and rivers commission, Government of Western Australia, December 1998.

2. Kumar M D, Tushaar S, The Hindu Survey of the Environment, 2004, 7-9, 11-12.

3. Sanjeev L, Dogra T D, Bhardwaj D N, Sharma R K, Murty O P and Aarti V, Indian J Clin Biochem., 2004, 19(2), 135-140. 
4. Preventing Groundwater Contamination, Fact Sheet, Michigan Department of Environmental Quality Environ Sci Services Division, 1994.

5. Rao N S, Hydrological Sci.J/J des Sci Hydrologiques, 2003, 48(5), 835-847.

6. Standard methods for the examination of water and waste water, 1985, $16^{\text {th }}$ Ed., APHA, AWWA and WPCF Inc. Newyork.

7. Palanisamy P N, Geetha A, Sujatha M, Sivakumar P and Karunakaran K, E J Chem., 2007, 4(3), 434-439. 


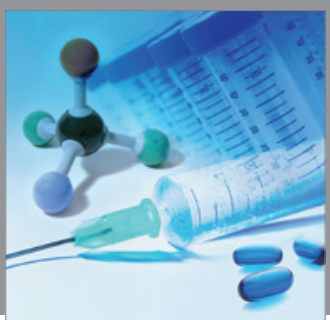

International Journal of

Medicinal Chemistry

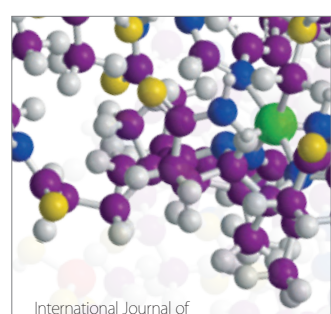

Carbohydrate Chemistry

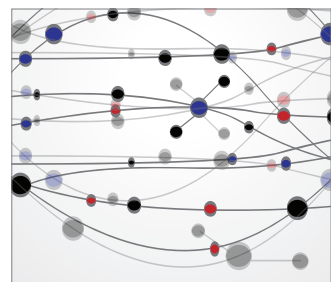

The Scientific World Journal
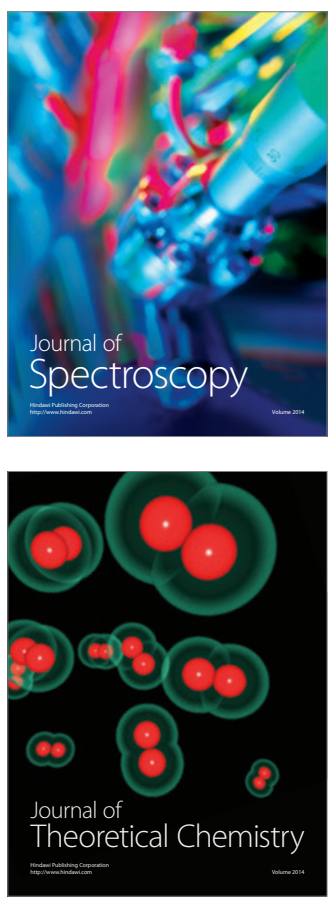
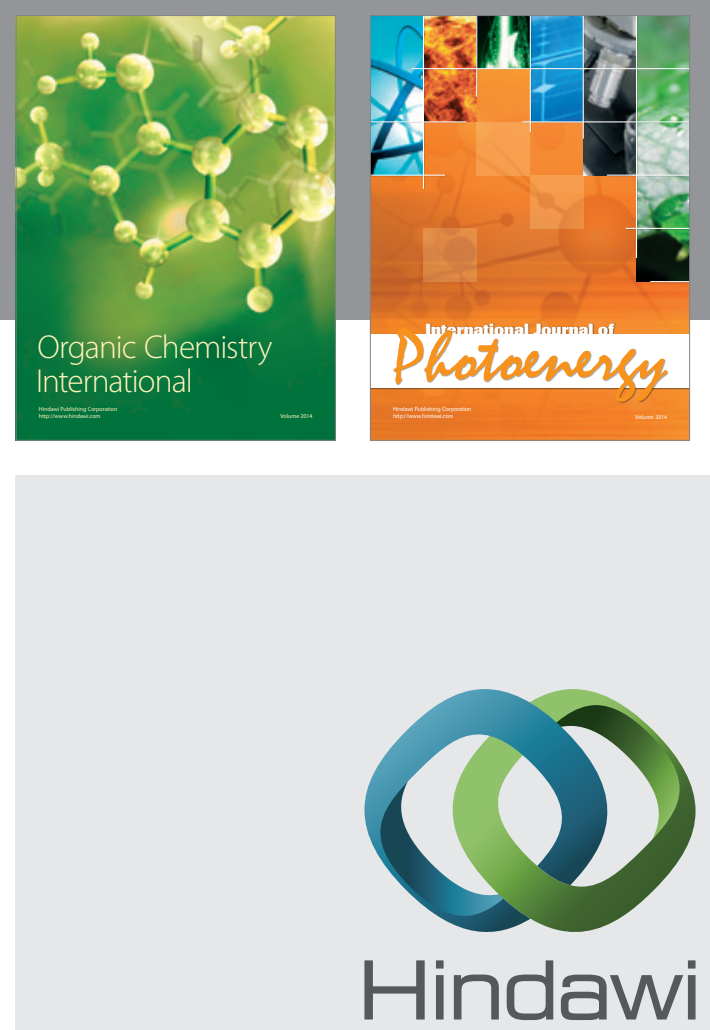

Submit your manuscripts at

http://www.hindawi.com
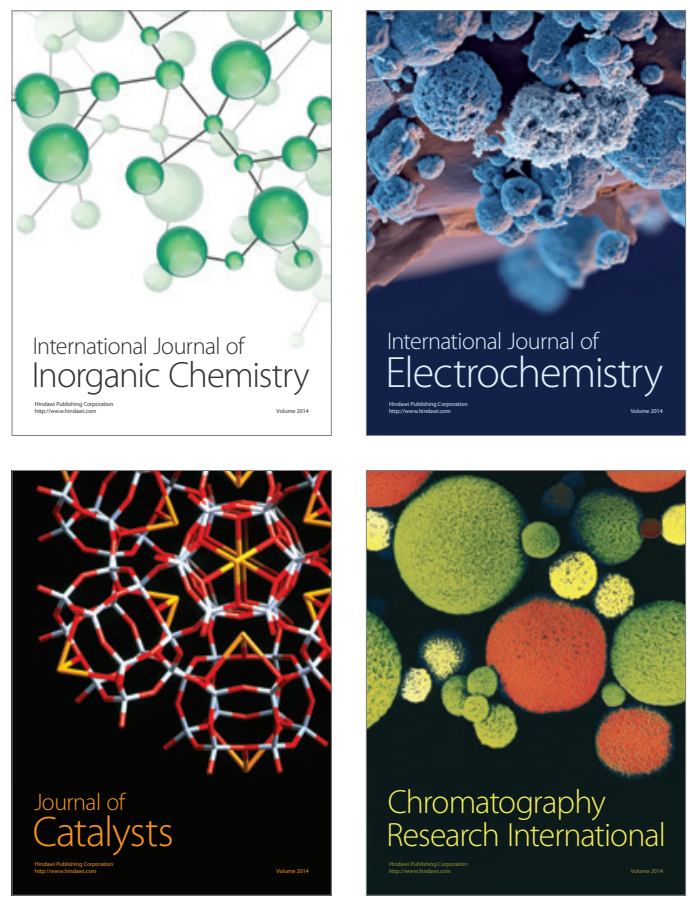
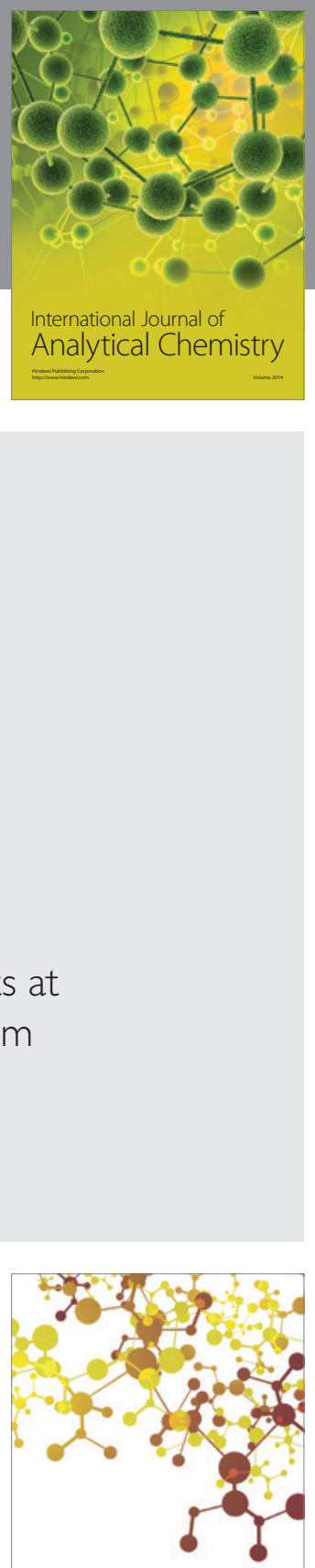

Journal of

Applied Chemistry
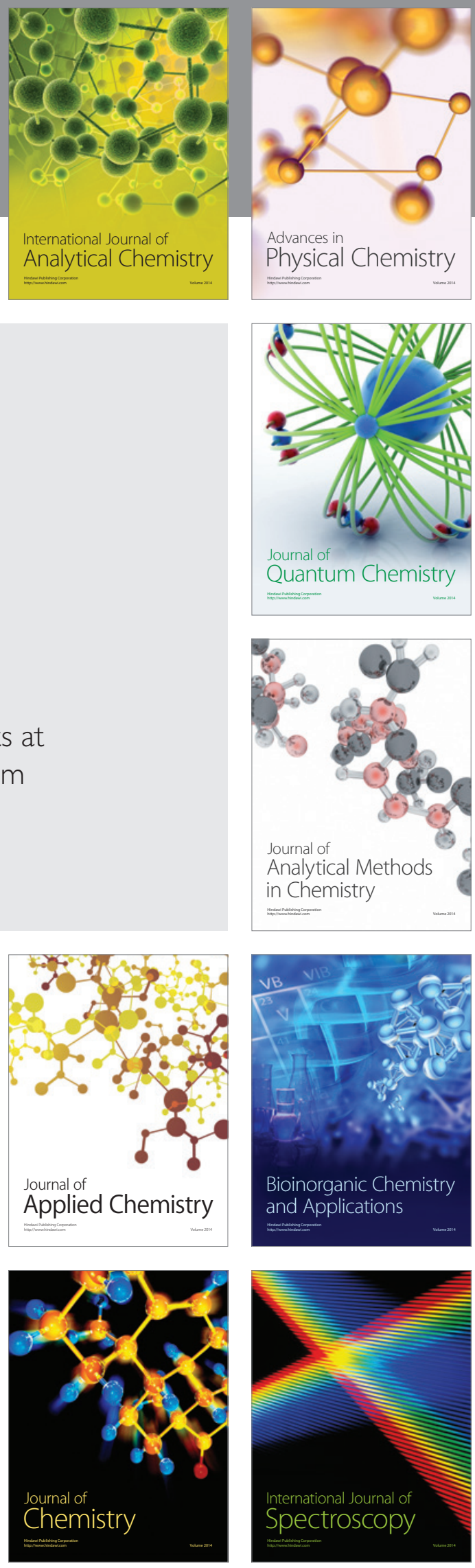